\title{
Publisher Correction: Bacillus SEVA siblings: A Golden Gate-based toolbox to create personalized integrative vectors for Bacillus subtilis
}

Jara Radeck $\mathbb{D}^{1,2}$, Daniel Meyer ${ }^{2}$, Nina Lautenschläger ${ }^{1}$ \& Thorsten Mascher $\mathbb{C}^{1}$

Correction to: Scientific Reports https://doi.org/10.1038/s41598-017-14329-5, published online 26 October 2017

The original version of this Article contained errors.

In the original HTML and PDF versions, there was a typographical error in the Discussion section where:

"The MCS or cargo and ori can easily be exchanged according to the SEVA standard and new or modified resistance markers can be inserted in markerless cargo vectors via MluI, e.g. markers flanked with target sites for recombinases".

now reads:

"The MCS or cargo and ori can easily be exchanged according to the SEVA standard and new or modified resistance markers can be inserted in markerless cargo vectors via AscI and MluI, e.g. markers flanked with target sites for recombinases".

The original PDF version of the Article was incorrectly marked as an uncorrected proof.

In addition, there was a typographical error in the caption of Table 1, where:

“d, destination vector/c, cargo vector/f, final vector".

now reads:

“d, destination vector. c, cargo vector. f, final vector".

Finally, a supplementary dataset containing the annotated DNA sequences files of the entry vectors in gbk-format was omitted from the original version of this Article.

These errors have now been corrected in the PDF and HTML versions of the Article.

${ }^{1}$ Institute of Microbiology, Technische Universität (TU) Dresden, 01062, Dresden, Germany. ${ }^{2}$ Department of Biology I, Ludwig-Maximilians-Universität (LMU) München, 82152, Planegg-Martinsried, Germany. Correspondence and requests for materials should be addressed toT.M. (email:Thorsten.Mascher@tu-dresden.de) 
(i) Open Access This article is licensed under a Creative Commons Attribution 4.0 International License, which permits use, sharing, adaptation, distribution and reproduction in any medium or format, as long as you give appropriate credit to the original author(s) and the source, provide a link to the Creative Commons license, and indicate if changes were made. The images or other third party material in this article are included in the article's Creative Commons license, unless indicated otherwise in a credit line to the material. If material is not included in the article's Creative Commons license and your intended use is not permitted by statutory regulation or exceeds the permitted use, you will need to obtain permission directly from the copyright holder. To view a copy of this license, visit http://creativecommons.org/licenses/by/4.0/.

(C) The Author(s) 2017 